\title{
DA ESPECIALIZAÇÃO À POLIVALÊNCIA: AS INFLUÊNCIAS ECONÔMICAS SOBRE A EDUCAÇÃO PROFISSIONAL E A NECESSÁRIA INTEGRALIZAÇÃO CURRICULAR
}

\author{
Carlos Farias da Silva*, Fábio Francisco de Almeida Castilho \\ E-mail: *carlosfarias_silva@hotmail.com \\ *Instituto Federal de Educação, Ciência e Tecnologia de Alagoas \\ DOI: $10.15628 /$ rbept.2020.9843
}

Artigo submetido em: abr./2020 e aceito em: maio/2020

\section{RESUMO}

Este artigo tem como objetivo discutir as interfaces entre a Educação Profissional e a economia, privilegiando três aspectos, a saber: a produção, o trabalho e a educação. Trata-se de um artigo de revisão da literatura, elaborado a partir do método do materialismo históricodialético. Os resultados apontam para a íntima relação existente entre a produção, o trabalho e a Educação Profissional, no contexto da economia de base capitalista. As conclusões indicam, ainda, que o impacto das influências econômicas sobre a concepção dos currículos e, por conseguinte, sobre a formação dos sujeitos, exige medidas de integralização curricular para evitar que a Educação Profissional sirva apenas ao atendimento das demandas pontuais de mercado, em detrimento da busca de uma formação omnilateral, cujo objetivo é o desenvolvimento das amplas capacidades humanas.

Palavras-chave: Educação Profissional. Trabalho. Capitalismo. Currículo.

\section{FROM SPECIALIZATION TO POLYVALENCE: ECONOMIC INFLUENCES ON PROFESSIONAL EDUCATION AND THE NECESSARY CURRICULAR INTEGRALIZATION}

\begin{abstract}
This article aims to discuss the interfaces between Professional Education and the economy, focusing on three aspects, namely: production, work and education. It is a literature review article, elaborated using the method of historical-dialectical materialism. The results point to the close relationship between production, work and Professional Education, in the context of the capitalist economy. The conclusions also indicate that the impact of economic influences on the design of curricula and, therefore, on the training of subjects, requires measures for curricular integration to avoid that Professional Education serves only to meet specific market demands, harming the search for omnilateral formation.
\end{abstract}

Keywords: Professional Education. Work. Capitalism. Curriculum. Curriculum integration.

\section{INTRODUÇÃO}

Nos estudos sobre Educação Profissional, um dos temas mais instigantes é a relação entre a produção da existência material e a formação humana. A maioria dos nexos entre essas duas categorias são explícitos, mas 
não necessariamente perceptíveis a olhares acríticos. Com efeito, se o trabalho for tomado como pilar fundamental das referidas categorias, as relações entre elas ganham maior nitidez. Isso porque o trabalho humano é o motor da produção da existência material; a educação, por sua vez, visa à formação dos sujeitos sociais, que contempla, entre seus objetivos, a qualificação para 0 trabalho.

A partir desse raciocínio, percebe-se que os modos de produção condicionam o processo formativo, ou seja, determinam a educação prestada aos sujeitos e, por isso, podem criar desencontros entre as dimensões ontológica e econômica do trabalho. Sem a devida integração entre essas dimensões, não se pode falar em currículo e formação integrados. Vista dessa forma, a relação entre trabalho e educação mostra-se essencial à compreensão dos mecanismos de elaboração dos currículos, já que estes são importantes instrumentos para a definição dos conteúdos, objetivos e diretrizes da formação que se pretende alcançar. Estes aspectos adquirem maior relevância quando pensamos a Educação Profissional e o percurso histórico de busca de uma educação integral, como se verá à frente.

Nesse sentido, este artigo discute a influência do modo de produção capitalista sobre a educação, especialmente suas consequências sobre a concepção curricular. Para tanto, fez-se um resgate histórico do mundo da produção, o que abrangeu duas fases do desenvolvimento capitalista recente: o fordismo e o toyotismo. Tais fases expuseram os interesses do capital sobre a educação, o que será estudado de modo mais específico e em uma perspectiva histórica, tendo por base o processo de industrialização brasileiro, sobretudo no período posterior a 1930.

Como será demonstrado adiante, os interesses capitalistas sobre a formação humana transitam da busca da especialização do operário fordista, durante o período da acumulação rígida, ao alcance da polivalência dos sujeitos, ao longo do período da chamada acumulação flexível, com reflexos diretos sobre a concepção curricular, especialmente da educação profissional.

As pressões do capital sobre a formação humana são fenômenos cíclicos e recorrentes, como a própria lógica da acumulação, e seus efeitos não se limitam a períodos estanques. Nesse sentido, as inovações tecnológicas e os desarranjos que elas provocam no mundo do trabalho remodelam e adequam os currículos educacionais, por vezes deixando lacunas, que devem ser preenchidas pelos sistemas de educação.

Antes, porém, de iniciar a discussão sobre currículos e integralização curricular, é necessário entender melhor a natureza dos laços entre a educação e a produção material. Essa tarefa foi facilitada pelo seguinte fato: as pretensões capitalistas, tão distintas quanto contraditórias, já foram objeto de inúmeros estudos ao longo das últimas décadas.

Por isso, para o alcance do objetivo do presente artigo, realizou-se uma pesquisa bibliográfica sobre o tema em livros, dissertações de mestrado, 
documentos legislativos, bem como em artigos científicos, publicados em revistas especializadas em Educação Profissional e áreas afins.

\section{AS FORÇAS ECONÔMICAS E SUAS INFLUÊNCIAS SOBRE AS SOCIEDADES HUMANAS}

Ao longo da história, a produção da existência material move as ações humanas na busca da manutenção das melhorias das condições de vida já alcançadas, bem como na descoberta e conquista de novas formas. Marx e Engels (1998), ao notar esse fenômeno, propuseram reinterpretar a história a partir dos diferentes modos pelos quais a humanidade produz sua existência material, ou seja, a partir da relação entre a acumulação material e as forças produtivas. Mais do que isso, Marx (1996) acreditava que as condições materiais da vida determinavam a consciência e o pensamento humanos, sendo, por isso, a causa das inúmeras modificações de todos os aspectos da existência humana. As forças econômicas, segundo tal raciocínio, seriam capazes de traçar os rumos da própria história.

Essa nova forma de enxergar o movimento do homem no tempo ficou conhecida como materialismo histórico-dialético, uma corrente teórica que faz "uma interpretação da história [...] à luz da compreensão dialética das regras, dos conflitos e do processo de desenvolvimento dos sistemas de trabalho" (SILVA ET. AL., 2015). Por esse prisma, a história pode ser definida como o processo de desenvolvimento das forças produtivas humanas. (GERMER, 2009).

Para melhor compreensão do pensamento marxista e de que modo as forças econômicas influenciam todos os âmbitos da vida humana, é preciso examinar os conceitos de "infraestrutura" e de "superestrutura", que constituem a metáfora do edifício utilizada no pensamento marxista. Era a partir dessa metáfora que Marx e Engels (1998) estudavam as sociedades humanas, com o propósito de esquadrinhar os elementos capazes de defini-las e de remodelálas ao longo do tempo.

Segundo a teoria marxista, a infraestrutura de uma sociedade é composta pelas condições naturais de produção, pelas forças de produção e pelas relações de produção. (MARX, 1996). As condições naturais de produção são compostas por elementos como o solo, o clima, o relevo, os recursos naturais etc., ou seja, dizem respeito basicamente ao ambiente natural em que a sociedade está inserida. As forças de produção, por sua vez, são representadas pela força de trabalho do próprio homem, bem como por equipamentos, maquinários, ferramentas, fábricas, armazéns, denominados genericamente de meios de produção. Já as relações de produção referem-se às relações travadas pelos trabalhadores entre si e àquelas travadas entre os trabalhadores e os seus empregadores. 
Nas relações de produção, situadas na infraestrutura social, estão inseridas questões centrais para a organização da sociedade, como a posse dos meios de produção e a divisão do trabalho. Essas duas questões representam a causa de um confronto permanente, um conflito histórico, que Marx (1996) denominou de luta de classes: uma luta dialética permanente entre os detentores dos meios de produção e os trabalhadores, sujeitos à espoliação e à exploração da sua força de trabalho.

As classes detentoras dos meios de produção exploram as classes despossuídas desses meios, não importa qual seja o modelo de sociedade existente. O produto da exploração humana é o que Marx (1996) chamou de "capital", algo que, segundo ele, existe desde os primórdios da humanidade, mas que tem assumido diversas formas ao longo da história. Entretanto, somente no capitalismo, o capital assume, de fato, o papel de protagonista do modo de produção. Nesse caso, o excedente de capital é aplicado na produção, que, ao se tornar mais eficaz, gera quantidades cada vez maiores de excedentes, os quais são novamente aplicados no processo produtivo para alimentar e iniciar um novo ciclo de acumulação. Essa lógica de acumulação cíclica e incontrolável é uma das principais características do capitalismo.

Meszáros (2011), ao tratar das formas históricas de produção, afirma que o capital subsistiu, inclusive, às chamadas sociedades pós-capitalistas. Essas sociedades tentaram superar 0 modo de produção capitalista, embaladas pelo objetivo de implantar o socialismo, mas acabaram por fracassar. O maior exemplo de sociedade pós-capitalista foi a própria União Soviética, berço e inspiração de experiências similares que ocorreram em outros lugares do mundo ao longo século XX.

Mészáros (2011) assevera, ainda, que os Estados pós-capitalistas, durante as investidas para implementar o socialismo, até conseguiram expropriar os expropriadores, ou seja, lograram êxito em retirar a burguesia da posse dos meios de produção; além disso, também teriam conseguido promover a eliminação jurídico-política da propriedade. Entretanto, segundo o autor, os elementos básicos constitutivos da divisão social hierárquica do trabalho não foram alterados nas sociedades pós-capitalistas. Sendo assim, a estrutura social antagônica, representada por uma hierarquia entre a classe dirigente e a classe trabalhadora permaneceu intacta. Ocorre que o domínio do capital se estabelece exatamente por intermédio de uma estrutura social antagônica, fundamentadora da exploração. Manter tal estrutura teria sido, segundo Mészáros (2011), uma das causas do insucesso, em todo o mundo, das inúmeras tentativas de implantação do socialismo.

Observe-se que 0 antagonismo entre as classes sociais é um elemento que faz parte da infraestrutura da sociedade, mais precisamente das relações de produção. Outros componentes da infraestrutura, como as condições naturais de produção, por exemplo, revelam uma importante relação entre o ser humano e o meio físico em que ele se estabelece: uma sociedade nômade não teria razões para desenvolver uma agricultura pujante ou construir cidades monumentais. Os limites naturais impõem obstáculos e condições que 
impulsionam o surgimento de culturas e sociedades necessariamente adaptadas às circunstâncias naturais postas (MARX, 1996).

Vê-se, por esse prisma, a importância dos componentes infraestruturais para a compreensão profunda de uma sociedade. Tais elementos, sucintamente, determinam o modo de produção utilizado por uma sociedade para produzir sua existência material. Nessa esteira, percebe-se que o capitalismo ${ }^{1}$ pode ser definido, de modo simples, como a posse privada dos meios de produção, ao passo que o comunismo ${ }^{2}$, por exemplo, define-se pela propriedade comum dos referidos meios.

A superestrutura, por sua vez, ao contrário da infraestrutura, é composta por elementos pouco palpáveis, mas não menos decisivos para a construção de uma sociedade. Para se ter uma ideia, entre os elementos superestruturais estão o direito, a moral, a cultura, os costumes, a ciência, a filosofia, a arte, a religião, o Estado e todo o seu aparato institucional. Estes últimos, aliás,

\footnotetext{
1 Segundo Catani (2017, p. 03-04), capitalismo é "um modo de produção de mercadorias, gerado historicamente desde o início da Idade Moderna e que encontrou sua plenitude no intenso processo de desenvolvimento industrial inglês, ao qual se chamou de Revolução Industrial. Por modo de produção de mercadorias entende-se tanto o modo pelo qual os meios necessários à produção são apropriados, como as relações que se estabelecem entre os homens a partir de suas vinculações ao processo de produção. A partir dessa perspectiva, capitalismo significa não apenas um sistema de produção de mercadorias, como também um determinado sistema no qual a força de trabalho se transforma em mercadoria e se coloca no mercado como objeto de troca. Para que exista capitalismo, faz-se necessária a concentração da propriedade dos meios de produção em mãos de uma classe social e a presença de uma outra classe para a qual a venda da força de trabalho seja a única fonte de subsistência".

2 Sob a luz do marxismo, de acordo com Lefebvre (2019), a democracia burguesa é um regime instável que caminha para a derrocada e consequente transformação. Tal crise pode resolverse de forma autoritária (bonapartismo) ou por um salto à frente em direção ao Comunismo. $\mathrm{Na}$ segunda opção, a democracia muda de sentido e a classe dominante se vê eliminada. $O$ Estado cessa de ser o órgão de ditadura burguesa e o proletariado assume a direção dos negócios, gerindo-os de acordo com seus interesses, que coincidem com os interesses da nação. Com efeito, os negócios públicos da nação passam a ser geridos de acordo com o sentido estabelecido pela grande maioria. No entanto, em Marx, esse processo só é possível quando organismos democraticamente controlados conseguem tomar a direção da indústria, das trocas comerciais e da agricultura, a fim de desenvolver as forças produtivas e organizálas racionalmente. Ou seja, é necessário que surja um novo tipo de Estado, o Estado socialista, e cada nação terá de descobrir sua própria fórmula de acordo com suas experiências, estruturas e forças que nela se enfrentam. Desse modo, o socialismo ainda comportaria um Estado, um funcionalismo e uma organização estatal e, portanto, ainda uma burocracia, um aparelho repressivo e um aparelho jurídico. Mesmo que o sentido desse novo Estado tenha mudado ainda persistem nele as sobrevivências e os prolongamentos das épocas passadas, isto é, a influência da classe anteriormente dominante ainda subsiste e precisa ser enfrentada. O Estado socialista é, portanto, a transição para o Comunismo que vai se transformando progressivamente. Por fim, o Comunismo se define pela liquidação definitiva dessas sobrevivências e de seus prolongamentos. $O$ comunismo se caracteriza pela superação $e$ supressão do Estado. Com o desaparecimento do Estado observa-se a transformação social nos seguintes aspectos: a) o desaparecimento das classes; b) um extraordinário desenvolvimento das forças produtivas; c) a superação da divisão do trabalho; d) um desabrochamento do indivíduo livre dentro de uma sociedade livre, onde o indivíduo encontra seu desenvolvimento total no social e não mais em oposição a esse.
} 
representam talvez o aspecto mais concreto da superestrutura, podendo, inclusive, valerem-se do uso da força para a consecução de seus objetivos.

Tais elementos, segundo Marx (1996), servem como um instrumental para a reprodução da infraestrutura. Antes disso, porém, a infraestrutura é um fator determinante da superestrutura, numa relação dialética que perpetua 0 modelo de sociedade e que mantém no poder os grupos detentores dos meios de produção. Em resumo, a infraestrutura determina a superestrutura; esta, por sua vez, reproduz aquela.

A partir dessa perspectiva, resta claro o fato de que os modos de produção, por comporem a base de uma sociedade, promovem severas influências na vida humana, desde os sistemas morais e filosóficos até os sistemas políticos e econômicos. Nesse sentido, para Silva et. al. (2015, p. 2)

dizer que a história é o desenvolvimento das forças produtivas tem por consequência a asserção de que todas as formas de organização social, política e econômica derivam daquelas relações primárias, que são as relações de trabalho entre os indivíduos.

Na mesma direção, é possível afirmar que os modos de produção, por irradiarem seus arcabouços ideológicos para todas as esferas de manifestação da vida humana, reproduzem as sociedades que os adotam. De modo recíproco, os sujeitos sociais produzem a força que move as engrenagens dos modos de produção existentes num dado momento histórico.

Dessa forma, é possível perceber a existência de uma simbiose, uma mútua dependência entre sociedades e formas de organização da produção material, a humanidade cria e depois sujeita-se aos ditames de uma "criatura" que não se deixa domar. Os modos de produção, seja o primitivo, o feudal ou o capitalista, demandam e forjam o sujeito que os perpetuam. O Feudalismo, por meio dos elementos superestruturais feudais, forjava o servo que trabalharia a terra e seria submisso aos interesses de seu senhor; o capitalismo, por sua vez, demanda o operário conhecedor das técnicas, das tecnologias e dos saberes que atendem aos interesses de acumulação do capital. (RAMOS, 2017).

A propósito, vale lembrar que as necessidades do capitalismo são dinâmicas e extremamente voláteis, pois o que está na origem do próprio sistema é a constante necessidade de revolucionar os meios de produção e, por consequência, os demais elementos da infraestrutura e da superestrutura sociais. (MARX, 1996). Por isso, ao longo das fases de desenvolvimento do capitalismo, a formação do trabalhador muda radicalmente de foco: ora se requer o operário especializado; ora se requer o trabalhador polivalente. Tudo depende das etapas da "metamorfose frenética" do capitalismo, sempre em busca das inovações tecnológicas, dos novos mercados, enfim, do 
atendimento das novas necessidades humanas, sejam elas reais ou criadas pelo sistema.

Nesse sentido, é possível afirmar que a corrente teórica do materialismo histórico-dialético teve o mérito de expor os nexos inquebráveis entre importantes categorias da vida humana, como o trabalho, a produção, a ciência e a educação. As relações entre essas categorias demonstram que, para além de exercer influências sobre a moral, os costumes, a política e etc., a organização da produção tem reflexos diretos no campo da educação, sobretudo na educação profissional. (RODRIGUES, 2007). Afinal, esta é a modalidade educacional que mais está conectada às determinações da infraestrutura social, pois tem como maior objetivo a formação para o trabalho, ou para o mercado de trabalho, utilizando uma expressão que define melhor os objetivos capitalistas. O foco é a preparação da classe trabalhadora para manter a produção em movimento. Como afirmam Afonso e Gonzalez (2016, p. 719),

a Educação Profissional e Tecnológica (EPT) é historicamente influenciada por diferentes concepções de formação, dentre elas a que defende uma formação voltada para atender aos anseios dos arranjos produtivos, ao modelo de desenvolvimento econômico, implicando em uma formação tecnicista com foco no mercado de trabalho.

Malgrado a formação para o trabalho seja um dos principais vetores da EPT, evitar erros em matéria de políticas educacionais passa pelo reconhecimento de que o trabalho humano é detentor de duas dimensões ou dois sentidos distintos: o ontológico e o econômico. O sentido ontológico expressa que "o trabalho é a ação humana de interação com a realidade para a satisfação de necessidades e produção de liberdade". (RAMOS, 2007, p. 03). Nesse contexto, Marx (1996) afirma que o trabalho é uma categoria que se define pela ação do homem sobre a natureza, a fim de transformá-la de um modo útil para vida humana; segundo o autor, ao modificar a natureza, o homem modifica a si mesmo, alterando a sua própria essência.

Para Frigotto (2012, p. 02), a concepção ontológica do trabalho, ou ontocriativa, como o autor também a denomina, "responde às necessidades da vida cultural, social, estética, simbólica, lúdica e afetiva". Saviani (1989, p. 08), por sua vez, corrobora essa ideia ao afirmar que a relação homem/trabalho é "o que define a existência humana, o que caracteriza a realidade humana é exatamente o trabalho. $O$ homem se constitui como tal, à medida em que necessita produzir continuamente a sua própria existência".

Já no sentido econômico, Ramos (2007, p. 03) afirma que o trabalho é a "forma histórica das relações sociais sob um modo de produção específico. Nas sociedades capitalistas a forma hegemônica do trabalho se dá pela venda e compra da força de trabalho, regulada contratualmente na forma de 
emprego". Sendo assim, nota-se que o sentido econômico é o aspecto do trabalho que mais se submete às mudanças históricas das formas de produção da vida material. É a dimensão econômica que, ao longo do tempo, assume as diversas formas históricas do trabalho: o servil, o escravo, o assalariado e etc.

No capitalismo, a valorização excessiva da dimensão econômica do trabalho pode provocar influências negativas na construção dos currículos educacionais. A depender das escolhas políticas, os currículos podem ter como meta a formação de sujeitos para atender unicamente as demandas pontuais do mercado, em detrimento de uma formação que prioriza o desenvolvimento das amplas capacidades humanas.

Percebe-se, assim, que o trabalho, em sua perspectiva essencialmente econômica, deixa-se atingir pelas vicissitudes dos tempos, as quais também atingem o processo educativo, no que concerne à função de educar para o trabalho. Ou seja, ao longo do tempo, as transformações do trabalho podem ser desprovidas do sentido ontológico que lhe é próprio.

Em razão disso, de todas as modalidades educacionais, a educação profissional é a que mais sofre as influências das mutações econômicas. Se as exigências do modo de produção se alteram, a educação dos sujeitos também se modifica no intuito de promover instrução para as novas formas assumidas pelo trabalho. Entretanto, como instrumento de promoção de cidadania e liberdade, a educação, ainda que deva acompanhar as transformações pelas quais o mundo passa, jamais deve ser alijada da contemplação das dimensões ontológica e econômica do trabalho, já que, somente dessa forma, é possível alcançar o pleno desenvolvimento das capacidades humanas.

\section{AS METAMORFOSES CAPITALISTAS E SEUS INFLUXOS NA EDUCAÇÃO PROFISSIONAL}

Ramos (2017) afirma que a escola possui uma relação histórica com o mundo da produção, cujas mudanças estruturam o princípio educativo do trabalho. Segundo a autora, durante o capitalismo, a pedagogia tradicional foi paulatinamente substituída pela chamada pedagogia nova. Para a pedagogia tradicional a finalidade da educação era transmissão de tradições de um grupo social às novas gerações; já para pedagogia nova a capacidade de pensar cientificamente representava uma necessidade dos novos tempos: a simples transmissão das tradições já não era suficiente para atender às novas exigências econômicas. Os pilares do pensamento dessa última corrente pedagógica estão atrelados ao conjunto das ideias que nutrem o capitalismo, pois a pedagogia nova surgiu no contexto da produção industrial.

Tendo em vista essa relação entre a Educação Profissional e o mundo da produção, Grabowski e Kuenzer (2016) fizeram uma análise das implicações do capitalismo sobre os processos educativos ao longo de duas fases emblemáticas do desenvolvimento capitalista recente: o fordismo e o 
toyotismo. As conclusões dos autores são contundentes ao expor a relação entre a educação e o mundo da produção, com fortes implicações para a concepção dos currículos e, por consequência, para a formação dos trabalhadores.

A fase fordista, guiada pelos princípios da administração científica do trabalho, de Frederick Taylor, também ficou conhecida pela denominação de acumulação rígida. Por oportuno, Mattoso (1995, p. 19) ressalta que o taylorismo teve como fundamentos três princípios

a) a dissociação do processo de trabalho das qualificações dos trabalhadores; b) a separação da concepção e da execução do trabalho e c) o uso do monopólio sobre o conhecimento para controlar os distintos passos do processo de trabalho e de seu modo de execução.

Os princípios do taylorismo provocaram a segmentação do processo produtivo fordista, fato que, segundo Grabowski e Kuenzer (2016), refletiu-se no campo da educação com a intensificação da dualidade educacional, por meio do fortalecimento das dicotomias educação geral/educação profissional, trabalho intelectual/trabalho manual, conhecimento teórico/conhecimento prático.

Nessa esteira, Ramos (2017) afirma que foi a lógica produtiva tayloristafordista que impôs à escola uma função econômica, ao configurá-la em sincronia com a divisão social, técnica e hierárquica do trabalho. Para a autora, a ideologia que lastreia essa nova lógica é a teoria do capital humano. Oriunda das ciências econômicas, essa teoria baseia-se na linearidade da relação entre - nível de escolaridade e a classificação social das pessoas; entre a escolaridade da população de um país e o seu desenvolvimento econômico. Ou seja, de acordo com essa teoria, quanto maiores os níveis de escolaridade, automaticamente, mais abastadas seriam as pessoas e mais desenvolvidos, os países. O equívoco desse pensamento, segundo a autora, é pressupor que o nível de escolaridade sempre corresponde ao nível de desenvolvimento de um país ou à classificação social de uma pessoa, quando na realidade essas situações dependem de múltiplos fatores. Níveis de escolaridade, classificação social e desenvolvimento econômico são, portanto, variáveis que não possuem entre si completa correspondência, como quer a teoria do capital humano. teoria,

Segundo Arapiraca (1979, p. 43), um dos críticos brasileiros a essa

A educação na teoria do capital humano não é tomada no sentido da promoção do desenvolvimento integral do cidadão, e, como tal, um bem de natureza ético-social, mas do ponto de vista do indivíduo e da análise econômica, como investimento 
capaz de produzir renda futura ou capital, posto que trata de grandezas definidas estatisticamente da perspectiva da instrução e do treinamento ou propriamente do sentido estrito de educação individual.

Percebe-se, assim, que o ideal da ampla formação dos sujeitos, a partir do desenvolvimento de suas amplas capacidades, não está contido nos propósitos da teoria do capital humano, que, como próprio nome sugere, não contempla a bidimensionalidade do trabalho, em seus sentidos ontológico e econômico. Pelo contrário, destaca exacerbadamente o primeiro sentido, em detrimento do segundo, relegando a segundo plano a formação humana plena. Na mesma esteira, ainda de acordo com Arapiraca (1979, p. 58),

\begin{abstract}
a teoria do capital humano não esclarece sobre o problema da reprodução dos meios de produção nem do fenômeno das classes sociais e sua reprodução. Os teóricos do capital humano tentam recortar o homem do seu complexo históricosocial e tratá-lo a partir da racionalidade da lógica da economia capitalista. Ela se circunscreve a tratar do problema da reprodução, que poderia ser considerada a partir de uma abordagem do fenômeno da apropriação da cota do sobretrabalho, para encarar as relações sociais de produção como um aspecto técnico e não social.
\end{abstract}

Interessante notar, também, que a percepção da relação entre qualificação e produtividade dos trabalhadores é mais antiga que a própria teoria do capital humano. De acordo com Saviani (1994), alguns teóricos, a exemplo de Adam Smith ${ }^{3}$, vislumbravam na educação básica dos trabalhadores, e somente nesta, contribuições para a acumulação do capital, pois esta tornaria a classe trabalhadora mais produtiva.

Reforçada por ideias como as de Adam Smith e as de teóricos do capital humano, a função econômica da escola, em conjunto com a gerência da produção fordista, teve como consequência direta a formação profissional de operários extremamente especializados. De acordo com Santos (2009), mais tarde, esses trabalhadores passariam por sérias dificuldades para se adaptar às modificações bruscas e recorrentes do mercado, o que levaria muitos ao desemprego e a compor o chamado exército de reserva.

Já a fase toyotista, também conhecida como acumulação flexível, de acordo com Rodrigues (1998), firmou as bases da produção capitalista em

\footnotetext{
${ }^{3}$ De maneira geral, os liberais do século XVIII percebiam que a educação voltada para os trabalhadores deveria ser pautada na utilidade para a produção. A educação ofertada aos trabalhadores deveria apresentar apenas o que era considerado essencial e deveria ser primordialmente instrutiva. A educação mais complexa e de maior qualidade deveria ser restrita aos bem nascidos e afortunados. Cf. Gruppi (1980).
} 
outro princípio: a eficiência do processo produtivo. Segundo o autor, as mudanças surgidas na fábrica Toyota, no Japão dos anos 1940-1950, foram reforçadas pela nova base técnica da microeletrônica, bem como por diversas inovações tecnológicas, como as redes internacionais de computadores, a informática, a comunicação por satélite e por fibra ótica. Tais inovações puseram em derrocada os métodos fordistas, que começaram a perder espaço nas indústrias e nos mercados. O toyotismo funda-se numa lógica de funcionamento inversa a do fordismo; trata-se de uma nova dinâmica de gestão do processo produtivo, cujo objetivo é o estoque zero. Uma das metas desse novo processo era a produção somente daquilo que fosse necessário, no tempo exatamente necessário. Estabeleceu-se, assim, uma cadeia de demanda do fim ao início, por meio da qual se objetivava a produção, em quantidades menores, de mercadorias de tipos diversos.

As mudanças implementadas pelo toyotismo provocaram severas transformações na educação, tendo em vista que o mercado passou a demandar das escolas o trabalhador flexível, multitarefa, polivalente, aquele capaz de adaptar-se às múltiplas situações de trabalho, nas mais diversas fases do processo produtivo. Segundo Grabowski e Kuenzer (2016), o trabalhador de tipo fordista, extremamente especializado, foi se tornando uma figura obsoleta, ante o processo de desespecialização iniciado pelo toyotismo.

Tamanhas mudanças, aliadas às inovações tecnológicas frequentes, impulsionaram a expansão da educação básica em vários lugares do mundo, inclusive no Brasil. A ampliação do acesso à educação, todavia, não era despropositado: tinha o claro intuito de proporcionar ao trabalhador a maleabilidade própria das novas exigências mercadológicas. Neste cenário estavam dispostas as características de uma Educação Profissional fragmentada e unilateral, mas não somente isso. De acordo com Ferretti (2009, p. 107),

o próprio desenvolvimento histórico da sociedade urbanoindustrial passou a exigir a expansão da educação escolar, não apenas em função do processo produtivo, mas também como resposta às demandas relativas ao desenvolvimento de hábitos necessários à vida nas cidades ou, em termos políticos, à formação do cidadão.

No Brasil, durante a Era Vargas, um organismo privado revelou-se "particularmente importante no processo de hegemonia da classe burguesa, em particular para a história das ideias pedagógicas: a Confederação Nacional da Indústria (CNI)". (RODRIGUES, 2007, p. 161). Entender o pensamento da $\mathrm{CNI}$ é uma chave para compreender como o ideário capitalista influenciou as ideias pedagógicas no Brasil.

Rodrigues (1998) afirma que a universalização da educação básica, por exemplo, inicialmente era vista pelo Estado brasileiro e pela própria CNI como 


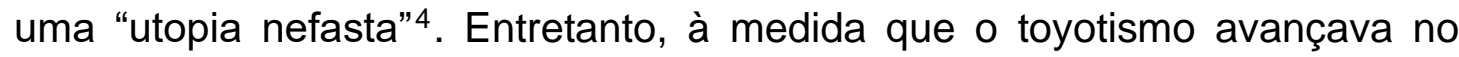
mundo, o discurso da $\mathrm{CNI}$ foi se adequando às novas exigências do capitalismo. Segundo o autor, foi assim que a ampla oferta de educação básica deixou de ser uma "utopia" e passou a ser vista como uma necessidade, uma medida imprescindível para o aumento da competitividade da indústria brasileira no cenário internacional. No período toyotista, portanto, ocorreu, de fato, uma valorização da educação, mas foi uma valorização interessada, cuja intenção era suprir as necessidades do mercado e das empresas, em detrimento, muitas vezes, da formação humana integral do trabalhador.

Em tempos de implementação do toyotismo em território brasileiro, competitividade, como visto, passou a ser a palavra central dos discursos sobre indústria e educação. Isso porque a educação torna-se o mais importante instrumento para o alcance da competitividade da indústria e das empresas. Durante essa fase do capitalismo, a teoria do capital humano ganhou ainda mais expressão no mundo; no Brasil dos anos 1950 aos 1970, por exemplo, essa teoria foi utilizada para orientar as políticas de educação da classe trabalhadora (RAMOS, 2017), o que intensificou ainda mais a função econômica da escola.

Com razão, Saviani $(1989$, p. 9) acentua que a sociedade moderna, "desenvolvida a partir do advento do capitalismo, é uma sociedade que revoluciona constantemente as técnicas de produção, que incorpora os conhecimentos como força produtiva". Por óbvio, as constantes revoluções das técnicas de produção lançam seus efeitos sobre a formação profissional, remodelando-a, conformando-a às novas tendências e exigências do capital.

José Rodrigues (1998), ao analisar o processo de industrialização brasileiro, expõe as implicações que as mudanças na produção exerceram sobre a educação nacional, observando maior efeito nas propostas relacionadas à Educação Profissional e o seu currículo. Para isso, o autor disseca as modificações ocorridas no pensamento pedagógico da CNI durante o fordismo e o toyotismo e de que modo essas mudanças se refletiram nas ações governamentais no campo da educação.

A partir do trabalho de Rodrigues (1998), foi possível perceber que o estudo do processo de industrialização é um dos caminhos para a compreensão das mudanças implementadas na educação de um país. Nesse sentido, o autor afirma que a industrialização brasileira ocorreu a partir da substituição de importações. Ou seja, o país começou a migrar de uma economia agrário-exportadora para uma economia industrial fazendo a substituição de mercadorias importadas, adquirindo bens de capital dos países do centro do capitalismo, bem como protegendo a indústria nascente, por meio da imposição de fortes barreiras alfandegárias.

A industrialização brasileira, porém, foi um processo multifatorial, conforme Rodrigues (1998), porque resultou não somente da substituição de

\footnotetext{
${ }^{4}$ Expressão utilizada pelo então Presidente-fundador da CNI, Euvaldo Lodi, para se referir à possibilidade de universalização da educação básica no Brasil (RODRIGUES, 1998).
} 
importações, mas também do estrangulamento das economias latinoamericanas a partir de 1914, em decorrência dos conflitos mundiais que se seguiram (Primeira e Segunda Guerras Mundiais). Nesse período, explica o autor, as economias dos países de capitalismo central voltaram-se para indústria de guerra e, concomitantemente, passaram a demandar menos produtos primários dos países de capitalismo periférico, como foi o caso do Brasil. Menos oferta externa de produtos industrializados, menos demanda por produtos primários nacionais, essa foi a combinação que propiciou o início da industrialização brasileira, levada a cabo por meio de medidas restritivas de importação, como elevação dos tributos sobre mercadorias estrangeiras.

Os fatores externos foram imprescindíveis, mas acontecimentos políticos internos também exerceram papel significativo na industrialização do Brasil, a exemplo da Revolução de 1930. Para Oliveira (2011, p. 35), esse fato marcou o "fim de um ciclo e o início de outro na economia brasileira: o fim da hegemonia agrário-exportadora e o início da predominância da estrutura produtiva de base urbano-industrial". Sobre o tema, Rodrigues (2007) afirma que a Revolução de 1930 teria soprado o "moderno espírito burguês-industrial" sobre um Brasil predominantemente agrário.

A indústria brasileira nasceu, portanto, impulsionada por fatos que abalaram as estruturas do capitalismo central, mas também foi produto de políticas estatais protecionistas, representadas pela reserva de mercado e pelas concessões indiscriminadas de incentivos, isenções e subsídios. Segundo Diniz (1997), não obstante passassem a existir no Brasil, no fim dos anos 1970, campanhas das elites industriais e comerciais contra a estatização da economia, ou seja, um movimento contrário às ações estatais anteriores, existiam também pressões para que a proteção estatal fosse mantida em relação a setores em dificuldade ou em fase de implantação.

Vale frisar que, para Rodrigues (1998), a industrialização brasileira se iniciou durante o auge do fordismo, e que, por isso, as concepções pedagógicas da CNI, no período compreendido entre 1930-1970, ficaram marcadas por valores fordistas. Houve, nesse intervalo, certa preocupação com a ampliação da educação básica, mas universalizá-la, como já expresso anteriormente, era uma ideia considerada utópica aos olhos da CNI.

Inserida numa "bolha" de protecionismo estatal, a economia brasileira não manteve sincronia com os ditames e transformações do capitalismo internacional. Em virtude disso, Rodrigues (1998) afirma que o Brasil completou sua industrialização de tipo fordista somente na década de 1980, época em que o fordismo já estava superado nos países capitalistas centrais. Por isso, a indústria nacional completou seu processo de implantação com uma estrutura ultrapassada, caracterizada pelas seguintes limitações: a) a incapacidade de competir com a nova indústria estrangeira de tipo toytotista; e b) a dependência de medidas estatais protecionistas para continuar existindo. Ainda assim, segundo o autor, a indústria nacional pretendia expandir-se para novos mercados, cujas regras de funcionamento seguiam patamares mais elevados de competição. Mais uma vez, foi necessário lançar-se sobre o 
terreno da educação; era preciso "modernizá-la" para formar trabalhadores aptos ao atendimento das exigências do novo padrão de acumulação.

Nesse período, o pensamento pedagógico hegemônico brasileiro modificou-se radicalmente para adaptar-se às novas tendências internacionais do mercado. Rodrigues (1998) relata que se passou a defender abertamente a universalização da educação básica, com a ampliação da quantidade de anos a serem contemplados por essa fase da vida educacional. Contraditoriamente, a "utopia nefasta" da universalização do ensino básico foi abandonada. Passou-se a defender que a educação teria o papel de desenvolver todas as potencialidades humanas, com o objetivo de formar o sujeito polivalente, multitarefa. Palavras como habilidade, competências, empregabilidade, também passam a marcar o ideário pedagógico. Aprender a aprender tornouse a principal habilidade a ser desenvolvida na escola, tendo em vista a flexibilidade do saber e a interdisciplinaridade do conhecimento. Nesse contexto, a polivalência do trabalhador passou a ser vista como um seguro contra o desemprego. Mais uma vez, $\mathrm{s}$ dificuldades percebidas na indústria e na produção apontavam os caminhos que a educação, em especial a Educação Profissional, deveria seguir no país.

Imbuída dos valores do novo padrão de acumulação (o toyotismo), a CNI também passou a alegar que a cultura empresarial brasileira (outro produto do protecionismo estatal) se tornara uma barreira à competividade das empresas e da indústria nacionais. Rodrigues (1998) afirma que se tratava de uma cultura anacrônica, ainda presa às exigências educacionais dos tempos fordistas, ou seja, uma cultura que não defendia a expansão da educação básica e que ainda continuava exigindo uma formação profissional especializada e restrita a um curto período da vida educacional.

Nota-se, assim, que o protecionismo fiscal e o isolacionismo da economia brasileira não permitiram que a indústria nacional sofresse as pressões por modernização, impostas pelo capitalismo além-fronteiras, ou seja, pelos fluxos de comércio internacional. No Brasil, o descompasso criado por tais medidas fez surgir o que Lipietz (1989) chamou de fordismo periférico, que se tratava de um tipo de fordismo que não completou todos os estágios atingidos pelo fordismo nos países de capitalismo central. Por aqui, não foram constituídos plenamente nem o Estado de bem-estar social, nem o mercado de massas, dois avanços sociais caracterizadores do fordismo propriamente dito, que promoveram alguns benefícios à classe trabalhadora, como o acesso a serviços públicos de qualidade e a partição no consumo de bens e serviços.

O modo como se processou o capitalismo brasileiro deu formas únicas e "exóticas" à estrutura econômica do país, tanto que Oliveira (2011, p. 60) afirma que a expansão do capitalismo no Brasil deu-se

[...] introduzindo relações novas no arcaico e reproduzindo relações arcaicas no novo, um modo de compatibilizar a acumulação global, em que a introdução das relações novas 
no arcaico libera força de trabalho que suporta a acumulação industrial-urbana e em que a reprodução de relações arcaicas no novo preserva o potencial de acumulação liberado exclusivamente para os fins de expansão do próprio novo. Essa forma parece absolutamente necessária ao sistema em sua expressão concreta no Brasil, quando se opera uma transição tão radical de uma situação em que a realização da acumulação dependia quase integralmente do setor externo, para uma situação em que será a gravitação do setor interno o ponto crítico da realização, da permanência e da expansão dele mesmo.

Ainda de acordo com Oliveira (2011), a combinação "aberrante" entre estruturas econômicas brasileiras altamente modernas e outras extremamente atrasadas teve como consequência o surgimento de um setor financeiro macrocefálico, sustentado por "pés de barro", ou seja, por setores econômicos arcaicos e frágeis. Na tentativa de buscar uma representação concreta capaz de dar formas ao capitalismo brasileiro, o autor o compara a um ornitorrinco, um animal semiaquático da fauna australiana, que impressiona pela mistura de características naturais: mamífero que não tem mamas, mas amamenta por meio de poros e sulcos abdominais, põe ovos e possui bico de pato, além de compartilhar genes com aves e mamíferos e ter características reptilianas, como a homeotermia imperfeita. A comparação por trás dessa metáfora de Oliveira (2011) é a de que, assim como o ornitorrinco é algo inusitado na linha da evolução das espécies, o Brasil representa o improvável na lógica da adaptação capitalista.

Para ilustrar o desenvolvimento anômalo da economia brasileira, Mendes (2015, p. 130) cita o período de 1968 a 1973, no qual o acentuado crescimento do chamado "milagre econômico brasileiro", em combinação com a elevada concentração de renda, "já revelavam os contornos de um país que não só se desenvolvia a partir de uma base desigual como dependia da manutenção dessa desigualdade para garantir a continuidade de seu torto processo evolutivo".

Pela confluência dos pensamentos, é possível notar a existência de um diálogo entre Rodrigues (1998) e Oliveira (2011), visto que esses pensadores contribuíram para a construção de um conceito sobre a economia brasileira, destacando as formas pouco convencionais da adaptação do capitalismo à realidade nacional e evidenciando as decorrências econômicas, políticas e sociais dessa adaptação. As teses dos dois autores se complementam e se entrelaçam ao desvelar um país marcado pelo desequilíbrio econômico, a desigualdade social cujos e reflexos podem ser percebidos nas políticas educacionais.

Como uma estrutura econômica tão atípica quanto a brasileira condiciona e adequa a escola às suas necessidades? Seria a metáfora do ornitorrinco aplicável ao sistema de educação do Brasil? As respostas a essas 
indagações podem ser dadas se, para tanto, os sérios problemas da Educação Básica e Profissional nacional forem considerados. Nesse sentido, é necessário reconhecer que todos e quaisquer avanços, por mais robustos que sejam, se ficarem restritos unicamente aos limites da educação superior, farão com que esta permaneça sustentada pelas estruturas fragilizadas da Educação Básica e Profissional. Assim, esta última poderia representar, na metáfora de Oliveira (2011), os "pés de barro" do sistema educacional brasileiro. Essa comparação entre sistema econômico e educacional não somente revela as influências de um sobre o outro, mas também reflete que, na realidade nacional, a metáfora do ornitorrinco pode ser aplicada à situação da educação brasileira.

Para além das discussões meramente metafóricas, é possível identificar, na prática, os reflexos da estrutura econômica anômala na educação brasileira: os setores desenvolvidos da economia necessitam de profissionais altamente capacitados, enquanto as estruturas arcaicas absorvem os trabalhadores sem qualificação, "mal formados", desprovidos do acesso a uma educação básica e/ou Profissional de qualidade.

Atualmente, as escolhas político-econômicas dos governos brasileiros, que fizeram do Brasil o Ornitorrinco de Oliveira (2011), continuam produzindo seus efeitos. Apesar de ter havido aumentos no investimento em educação no Brasil, em 2018, "nenhum estado atingiu a meta do Índice de Desenvolvimento da Educação Básica (Ideb) 2017. Além disso, cinco estados brasileiros apresentaram redução no valor do Ideb". (BRASIL, 2018).

O momento político e econômico atual também não tem sinalizado a superação dos desafios da educação brasileira, tendo em vista que o problema fiscal vivido pelo país, nos últimos anos, trouxe à tona exigências antigas do padrão de acumulação flexível, como a flexibilização das relações trabalhistas, a reforma da previdência e a redução do Estado. Essas exigências, de natureza neoliberal, segundo Melo (1991) ferem os princípios fundadores do Welfare State, quais sejam: a seguridade social e a proteção ao trabalho.

Na prática, essas medidas são hoje representadas pelo teto dos gastos públicos, instituído pela Emenda Constitucional ํo 95/2016, que congela os gastos do Estado por vinte anos; a reforma trabalhista, implementada pela Lei no 13.467 de 2017; e a Emenda à Constituição № 103/2019, a tão discutida reforma da previdência.

$\mathrm{Na}$ contramão das contas públicas, a modernização da educação, um dos pilares fundamentais para o desenvolvimento econômico do país, bem como para saída efetiva de qualquer tipo de crise, exige investimentos vultosos e frequentes. Entretanto, é provável que o destino dos recursos financeiros seja o pagamento dos juros e a amortização da elevada dívida pública brasileira.

Se essas medidas se concretizarem, ações de melhorias da educação, que já são urgentes, continuarão sendo adiadas. Ademais, se forem considerados os desafios impostos pelo conjunto de transformações atuais, 0 cenário pode ser ainda mais incerto. Os desarranjos sociais projetados para 0 
futuro do mundo do trabalho e da produção por pesquisas como a de Frey e Osborne (2013) poderão ser ainda mais graves, se aliados a uma escola que não consegue superá-los.

A possibilidade da ocorrência desses desarranjos sociais não são simples previsões estatísticas acerca de um futuro sobre o qual ninguém tem controle. Pelo contrário, as experiências passadas oferecem visões nítidas sobre a dinâmica do mundo do trabalho em consequência de transformações tecnológicas. Mattoso (1995, p. 9), por exemplo, lembra as consequências, para o trabalho, da segunda revolução industrial

Os impactos são desestruturadores da sociedade de massa criada pela Segunda Revolução Industrial: é nula a criação líquida de empregos industriais; modifica-se profundamente a organização dos processos fabris; altera-se completamente o perfil de habilidades, educação e qualificação dos trabalhadores, enfraquece-se a base sindical organizada; aprofunda-se a automação on line, flexível e abrangente; poupa-se intensamente o capital-de-giro com a minimização dos estoques; enxugando-se o sistema de administração das empresas com a supressão de níveis hierárquicos e terceirizações; articulam-se redes eletrônicas de suprimento com fornecedores e distribuidores.

Num futuro próximo os desarranjos no mundo do trabalho poderão ser tão intensos quanto aqueles ocorridos nas revoluções anteriores. A pesquisa realizada por Frey e Osborne (2013) estima que aproximadamente 47\% dos empregos nos Estados Unidos estão ameaçados pelo efeito potencial da inovação e poderão ser extintos nas próximas duas décadas. Profissões como operadores de telemarketing, avaliadores de seguros, árbitros, juízes e outros profissionais desportivos, secretários jurídicos, corretores de imóveis e mão de obra agrícola possuem alta probabilidade de serem extintas em razão dos processos de automação. Ainda segundo conclusões da mesma pesquisa, as ocupações e cargos criativos e cognitivos de altos salários são os menos propensos à extinção.

No Brasil, segundo Albuquerque et. al. (2019), uma pesquisa realizada pelo Laboratório de Aprendizado de Máquina em Finanças e Organizações da UnB (LAMFO), concluiu, por meio de estudos que utilizaram a mesma metodologia da pesquisa feita por Frey e Osborne (2013), que cerca de 30 milhões de empregos estarão em risco até 2026, caso as empresas resolvam automatizar os postos mais propensos à substituição por máquinas. Esse cenário de ampla automatização é o mais provável para o futuro próximo, visto que as máquinas podem aumentar a eficiência das empresas e reduzir seus custos. 
Todas essas estatísticas demonstram o tamanho do desafio a ser vencido pela educação, o que necessariamente toca temas relacionados não somente ao financiamento do sistema, mas principalmente àqueles relacionados à concepção dos currículos. Afinal, é nesses instrumentos em que se inscreve as diretrizes, bem como tudo o que é preciso para "formar os homens que o Brasil necessita [...]" (RODRIGUES, 2007, p. 176), para usar uma expressão do Presidente-fundador da CNI, Euvaldo Lodi.

\section{A CONCEPÇÃO CURRICULAR E A INTEGRALIZAÇÃO NECESSÁRIA}

Não se pode ter certeza de quais serão os reflexos na educação dos acontecimentos recentes da história brasileira e das últimas transformações do capitalismo. A Educação Profissional continua como um passageiro passivo das decisões políticas em um cenário de transformações econômicas e as suas demandas não são consideradas. Entretanto, os nexos existentes entre a produção material e a educação sugerem que a receita a ser seguida já é bem conhecida: utilizar os sistemas de educação como instrumento para aprimorar a competitividade da indústria e das empresas, bem como para promover a melhoria da produção, com a consequente realização dos interesses do capital, seguindo a nova lógica de acumulação.

A origem e o desenvolvimento da educação profissional no Brasil demonstra que a previsão do parágrafo anterior poderá ser confirmada, visto que essa modalidade educacional surgiu com caráter predominantemente assistencialista, cujos objetivos, por um lado, era afastar seus potenciais alunos da prática de condutas contrárias aos bons costumes e à ordem pública e, por outro, também formar "mão de obra" para as fábricas e empresas. Nesse sentido, Vieira e Veira (2016) afirmam que, com esta característica embrionária, a educação profissional continua servindo ao modelo de desenvolvimento econômico e sofre alterações para atender a particularidades típicas do desenvolvimento capitalista.

Resta saber se, após o desenrolar dos embates políticos, os currículos e suas novas diretrizes priorizarão a formação profissional para o atendimento exclusivo das demandas do mercado, ou se, para além disso, buscarão reservar espaço para a implementação de instrumentos que possibilitem a formação omnilateral e emancipadora dos sujeitos.

Entretanto, sinais de qual será a direção tomada já são perceptíveis. A reforma do ensino médio, promovida pela Medida Provisória (MP) no 746/2016, posteriormente convertida na Lei 13.415/2017, dá uma noção clara dos rumos que estão sendo seguidos pelo Brasil na reformulação de seu sistema educacional. Consoante Moraes (2017, p. 422), essa reforma impede 0 "exercício do direito ao conhecimento propiciado pela educação de base, comum a todos, universalizada". Segundo o autor, por intermédio das medidas adotadas na reforma, propôs-se o estabelecimento de um currículo mínimo no ensino médio, com base no modelo das competências. Esse modelo, por sua 
vez, observou as definições da Organização para a Cooperação e Desenvolvimento Econômico (OCDE), cujo objetivo, segundo o autor, é atender aos interesses do mercado globalizado e flexível.

Diante do exposto, para identificar os fins almejados por uma sociedade, em termos de Educação Profissional, é preciso responder algumas indagações, tais quais: que seres humanos devem ser formados nas escolas? O tipo mutilado, que atende unicamente às exigências impostas pelo mercado? Ou o tipo emancipado, que, para além de movimentar as engrenagens do sistema produtivo, é capaz de pensar criticamente a sociedade, de compreendê-la em sua plenitude e complexidade?

Inexoravelmente, esses questionamentos despertam discussões acerca dos currículos, instrumentos que delineiam a formação humana, ao traçar os caminhos e os fins que o processo educativo deve atingir. Não por acaso, o espaço curricular é visto como um ambiente de conflito entre múltiplos interesses, por isso pode ser comparado a uma "arena" de contínuos embates.

Nesse sentido, vale frisar que Frigotto e Ciavatta (2003, p. 97) afirmam que "ocorre uma disputa entre o ajuste dos sistemas educacionais às demandas da nova ordem do capital e as demandas por uma efetiva democratização do acesso ao conhecimento em todos os seus níveis". Por conta disso, o currículo constitui-se "em um espaço de luta entre as classes dominantes e as subalternas, refletindo a '[...] exploração e a luta contra a exploração'”. (ARAUJO; FRIGOTTO, 2015, p. 67). Rodrigues (1998, p. 135), por sua vez, também ressalta que, não somente o currículo, mas a educação como um todo "é permanentemente campo de luta hegemônica para a definição de seus fins, seus objetivos, seus métodos e estrutura".

Sendo assim, a escola e o currículo constituem-se como espaços de contradição, pois tanto podem abrigar concepções transformadoras quanto conformadoras da realidade presente, uma vez que são verdadeiras correias de transmissão da ideologia oficial. (ARAUJO; FRIGOTTO, 2015). Em virtude dessa constatação, é possível afirmar que mudanças curriculares geram impactos na produção/reprodução da sociedade, fato que demonstra a importância da definição curricular, enquanto diretriz central da formação dos sujeitos sociais.

A definição adequada dos currículos, ao menos daqueles que se pretendam integrados, devem ter como baliza o princípio educativo do trabalho, visto que este representa a mediação entre o ser humano e a natureza. É nessa mediação que se dá a produção do conhecimento: a ação do homem sobre a natureza gera, inicialmente, conhecimentos empíricos. Em seguida, ao orientar de forma sistematizada os conhecimentos empíricos adquiridos, a humanidade produz o conhecimento científico. Por meio desse processo de produção de conhecimentos, o objetivo da humanidade é viabilizar a produção da sua existência material. Existe, portanto, uma unidade entre o conhecimento e o trabalho, daí a importância de a escola adotar o trabalho como princípio educativo, como balizador das atividades educacionais. (RAMOS, 2017). 
Os esforços para que os currículos estabeleçam o trabalho como princípio educativo são também esforços para que os processos educativos contemplem as dimensões ontológica e econômica do trabalho. A transformação social ampla e emancipadora deve ser o escopo maior da educação concebida para além do capital (MÉSZÁROS, 2008) e deve ter em vista o desenvolvimento das mais diversas capacidades humanas, por intermédio da politecnia, não no sentido literal do termo (múltiplas técnicas, multiplicidade de técnicas), mas na acepção que Ihe confere Saviani (1989, p. 17), ao defini-la como

o domínio dos fundamentos científicos das diferentes técnicas que caracterizam o processo de trabalho produtivo moderno. Diz respeito aos fundamentos das diferentes modalidades de trabalho. Politecnia, nesse sentido, se baseia em determinados princípios, determinados fundamentos e a formação politécnica deve garantir o domínio desses princípios, desses fundamentos.

Vale destacar que a educação politécnica pressupõe a superação de correntes pedagógicas hegemônicas, como a pedagogia das competências, que se apega exacerbadamente à realidade presente e se pauta por demandas pontuais e específicas do mercado de trabalho. Tal corrente pedagógica, segundo Araujo e Frigotto (2015), só pode formar o sujeito humano mutilado e conformado, tanto do ponto de vista político quanto pedagógico. Isso ocorre porque os interesses do capital sempre poderão abrir lacunas curriculares, que exigirão ações de integralização por parte de todos os atores do universo da educação.

Fica mais fácil perceber o que essas lacunas curriculares representam na prática a partir da leitura de uma célebre frase de Adam Smith: "Instrução para os trabalhadores sim, porém, em doses homeopáticas". Essa afirmação, conforme Saviani (1989, p. 14), "significa que os trabalhadores têm que dominar aquele mínimo de conhecimentos necessários para serem eficientes no processo produtivo, mas não devem ultrapassar este limite".

Se ofertada de forma generosa, "a educação poderia voltar-se contra os interesses do capital, pois o saber adquirido converteria os trabalhadores em proprietários de um dos meios de produção (o conhecimento de base científica)". (FERRETTI, 2009, p. 108). Esse tipo de pensamento privilegia unicamente o aumento da produtividade do trabalhador, em detrimento de sua formação plena. Afinal, num currículo concebido a partir de raciocínios como esse, haveria lugar para a dimensão ontológica do trabalho, para promoção da politecnia e da cidadania? Certamente não.

São complexas as discussões sobre o termo integrado e os sentidos que Ihe são atribuídos em expressões como "currículo integrado", "ensino médio integrado", "formação integrada" e "Ensino Profissional Integrado". A busca de 
sinônimos em dicionários não revela completamente o significado do termo, quando utilizado nessas expressões. No caso da expressão "formação integrada", por exemplo, Vieira e Vieira (2016, p. 83) apontam que esta "pressupõe a integração epistemológica, de conteúdo, de metodologias e de práticas educativas, refere-se à integração teoria-prática, entre o saber e o saber-fazer". Já Artuso e Maciel (2018) afirmam que o currículo integrado é uma forma de operacionalização e de sintetização da relação entre os saberes acumulados pela humanidade.

Vieira e Vieira (2016) afirmam, ainda, que a formação integrada não deve ser confundida com simples articulação de currículos do ensino médio e técnico profissional, visto que os esforços para articulação, muitas vezes, visam a responder questões simplistas, do tipo: a educação geral e a profissional devem ocorrer de modo separado (com currículos distintos)? Nesse caso, caberia discutir apenas se as duas modalidades de educação seriam oferecidas simultaneamente ou de forma subsequente. Entretanto, a ideia de integração parece ir além dessa preocupação, quando se defende que não se deve pensar apenas em dois currículos e de que modo os articular. $O$ que está em discussão é como, a partir dos diferentes conteúdos, criar um currículo único (o currículo integrado), que abranja os saberes da educação geral e da profissional, como elementos inseparáveis.

Recompor a noção do todo e eliminar as dualidades e dicotomias na educação deve ser um dos objetivos principais das discussões sobre ensino médio profissional, currículo e formação integrados. Entretanto, para o alcance desse objetivo, deve-se partir da compreensão das relações existentes entre os modelos econômicos e a educação. Ou seja, de que modo os interesses econômicos moldam os currículos de acordo com suas necessidades, as quais, no capitalismo especificamente, são guiadas pela lógica da acumulação e do lucro.

Propor soluções para o problema e encontrar meios para a implementação de um currículo integrado são atitudes que não podem prescindir da compreensão das origens mesmas do problema e de suas metamorfoses ao longo do tempo, as quais demandam, num primeiro momento, determinados perfis de formação profissional para, num segundo momento, descartá-los.

Percebe-se, assim, que um dos grandes desafios da pesquisa na área de educação, com desdobramentos específicos quanto à Educação Profissional, é descobrir formas de implementação do currículo integrado, que vislumbrem, ao menos a longo prazo, a promoção de uma educação emancipadora e transformadora.

Nesse sentido, vale destacar o papel que os mestrados profissionais em Educação Profissional podem assumir não somente no aprofundamento da compreensão das relações entre economia e educação, bem como dos problemas que decorrem dessas relações, mas também na tarefa de propor e viabilizar soluções práticas para parte dos problemas existentes. Tal empreitada pode ser levada a cabo por meio do desenvolvimento de produtos 
educacionais para os mais diversos assuntos e problemas enfrentados no cotidiano da educação. Como resultados das pesquisas realizadas nos mestrados profissionais, os produtos educacionais precisam ser validados e, para isso, devem atender alguns critérios, tais como a aplicabilidade imediata nas realidades trabalhadas pelos pesquisadores (LEITE, 2018).

Essa exigência pode colaborar para que os produtos educacionais busquem, cada vez mais, articular teoria e prática e, com isso, levar adiante 0 enfrentamento efetivo das dualidades educacionais e, por conseguinte, das deficiências curriculares e formativas, ao propor soluções que vislumbrem estratégias didáticas inovadoras e que promovam uma formação guiada pela ideia de omnilateralidade, sobretudo no contexto da Educação Profissional.

\section{CONSIDERAÇÕES FINAIS}

Pelo exposto, é possível perceber que os modos de produção sempre influenciaram a concepção dos currículos, o que ficou ainda mais evidente na discussão feita em torno de dois momentos da economia capitalista: o fordismo e o toyotismo (GRABROWSKI; KUENZER, 2016). Visto que no primeiro, para atendimento das necessidades de acumulação do capital, exigia-se do trabalhador uma formação especializada, ao passo que no segundo momento passou-se a exigir uma formação polivalente e flexível que permitisse ao trabalhador adaptar-se aos mais diferentes postos e situações de trabalho. Ambos os modelos não promovem a integralização da educação ou a sua omnilateralidade.

Os efeitos desses dois momentos do capitalismo no Brasil também foram objeto de discussão, sobretudo no período posterior a 1930, em que se iniciou o processo de industrialização do país. A análise das concepções pedagógicas da CNI, feita por Rodrigues (1998), revelaram que as influências econômicas sobre a educação brasileira não foram diferentes das que ocorreram em outros lugares do mundo. Entretanto, no Brasil, tal fenômeno ocorreu de forma retardada em razão das políticas protecionistas que isolaram, de certo modo, o país das transformações capitalistas internacionais. Esse fato deu origem ao que Lipietz (1989) chamou de fordismo periférico. No Brasil, segundo Rodrigues (1998), o fordismo periférico teve como uma de suas consequências o prolongamento de uma cultura empresarial anacrônica, relutante à universalização da educação básica, que passou a ser defendida, nos países de capitalismo central, após o advento do toyotismo e da necessidade de trabalhadores flexíveis e polivalentes.

As discussões feitas neste artigo permitiram concluir que a formação integrada e omnilateral dos sujeitos, ao lado da busca de uma Educação Profissional mais humana e integrada, apontam para a necessidade de os currículos serem integralizados, de modo que contemplem o trabalho em suas dimensões ontológica e econômica para, assim, promoverem a formação humana integrada. 
As ações de integralização prestam-se, portanto, a preencher lacunas curriculares da Educação Profissional decorrentes das influências dos mais diversos interesses, especialmente econômicos, sobre a formação humana. Esses interesses podem reduzir essa formação a uma simples preparação para o mercado de trabalho, circunstância que nega ao ser humano o direito a uma educação plena, capaz de articular trabalho, ciência, tecnologia e cultura.

Ademais, discutiu-se que é preciso recompor na educação a ideia do todo, a articulação entre teoria e prática, guiada pelo princípio educativo do trabalho e, assim, viabilizar a implementação de um currículo integrado no sentido epistemológico dessa expressão. O propósito disso é o alcance de uma formação humana integrada que supere as dualidades educacionais.

Vale o registro de que a formulação de um currículo integrado deve ser precedida de uma ampla compreensão das relações entre economia e educação, visto que essas relações podem explicar o processo de concepção curricular e revelar a razão de ser de currículos que surgem para atender a interesses e demandas pontuais do mercado, em detrimento de uma formação humana plena.

Por fim, foi destacada a contribuição que os mestrados profissionais podem prestar para busca de uma formação omnilateral no contexto da educação profissional, por meio do desenvolvimento de produtos educacionais que criem soluções práticas para inúmeros problemas enfrentados pela educação.

\section{REFERÊNCIAS}

AFONSO, A. M. M.; GONZALEZ, W. R. C. Educação Profissional e Tecnológica: análises e perspectivas da LDB/1996 à CONAE 2014. Ensaio: aval.pol.públ.Educ., Rio de Janeiro, v. 24, n. 92, p. 719-742, set. 2016. Disponível em: <http://www.scielo.br/scielo.php?script=sci_arttext\&pid=S0104403620160003 00719\&lng=pt\&nrm=iso $>$. Acesso em: 07 fev. 2020. http://dx.doi.org/10.1590/S0104-40362016000300009.

ALBUQUERQUE, P. et. al.. Probabilidade de automação nas ocupações brasileiras. Lamfo, 2019. Disponível em: <https://lamfo.shinyapps.io/automacao/>. Acesso em: 20 fev. 2020.

ARAPIRACA, J. O. A USAID e a educação brasileira: um estudo a partir de uma abordagem crítica da teoria do capital humano. 1979. 273p. Dissertação (Mestrado em Educação - FGV - Fundação Getúlio Vargas, Rio de Janeiro, 1979. Disponível em: <http://hdl.handle.net/10438/9356>. Acesso em: 31 jan. 2020.

ARAUJO, R. M. L; FRIGOTTO, G. Práticas pedagógicas e ensino integrado.

Revista Educação em Questão, v. 52, n. 38, p. 61- 80, 2015. Disponível em: 
<https://periodicos.ufrn.br/educacaoemquestao/article/viewFile/7956/5723>. Acesso em: 21 jan. 2020.

ARTUSO; A. R.; MACIEL; P. D. Trabalho por projetos na Educação Profissional e Tecnológica - um panorama de diferentes visões. In: Eduardo Fofonca; Glaucia da Silva Brito; Marcelo Estavam; Nuria Pons Villardel Camas. (Org.). Metodologias pedagógicas inovadoras: contextos da educação básica e da educação superior. 1ed.Curitiba: Editora IFPR, 2018, v. 1, p. 77-87. Disponível em: https://reitoria.ifpr.edu.br/wpcontent/uploads/2018/08/E-book-Metodologias-Pedag\%C3\%B3gicasInovadoras-V.1_Editora-IFPR-2018.pdf>. Acesso em: 10 jan. 2020.

BRASIL. Instituto Nacional de Estudos e Pesquisas Educacionais Anísio Teixeira. Nenhum estado atinge a meta do Ideb 2017 no ensino médio. 2018. Disponível em: http://portal.inep.gov.br/artigo//asset_publisher/B4AQV9zFY7Bv/content/nenhum-estado- atinge-a-meta-doideb-2017-no-ensino-medio/21206. Acesso em: 14 jan. 2020.

CATANI, A M. O que é capitalismo. 25 Ed. São Paulo: Brasiliense, 2017.

DINIZ, E. Crise, reforma do Estado e governabilidade: Brasil, 1985-95. Rio de Janeiro: Editora Fundação Getúlio Vargas, 1997.

FERRETTI, C. J. O pensamento educacional em Marx e Gramsci e a concepção de politecnia. Trabalho, Educação e Saúde, v. 7, n. 1, p. 105128, 2009. Disponível: http://www.scielo.br/pdf/tes/v7s1/06.pdf. Acesso em: 12 jan. 2020.

FREY, C. B.; OSBORNE, M. The future of employment. 2013. Disponível em: https://www.oxfordmartin.ox.ac.uk/downloads/academic/The_Future_of_Empl oyment.pdf. Acesso em: 15 fev. 2020.

FRIGOTTO, G.; CIAVATTA, M. Educação básica no Brasil na década de 1990: subordinação ativa e consentida à lógica do mercado. Educação e Sociedade, v. 24, n. 82, p. 93-130, 2003. Disponível em: http://www.scielo.br/pdf/es/v24n82/a05v24n82.pdf. Acesso em: 12 fev. 2020.

FRIGOTTO, G. Concepções e mudanças no mundo do trabalho e o ensino médio. In: FRIGOTTO, G.; CIAVATTA, M.; RAMOS, M. (Orgs.). Ensino Médio Integrado: concepções e contradições. 3. ed. São Paulo: Cortez, 2012.

GERMER, C. M. Marx e o papel determinante das forças produtivas na evolução social. Crítica Marxista, v. 29, n. 1, p. 75-95, 2009. Disponível em: ifch.unicamp.br/criticamarxista/arquivos_biblioteca/artigo172artigo2.pdf. Acesso em: 05 jan. 2020.

GRABOWSKI, G.; KUENZER, A. Z. A produção do conhecimento no campo da Educação Profissional no regime de acumulação flexível. Holos, v. 6, p. 
22 32, 2016. Disponível em:

http://www2.ifrn.edu.br/ojs/index.php/HOLOS/article/view/4983. Acesso em: 06 jan. 2020.

GRUPPI, L. Tudo começou com Maquiavel (as concepções de Estado em Marx, Engels, Lenin e Gramsci). Porto Alegre: L \& PM editora, 1980.

LEFEBVRE, H. Marxismo: uma breve introdução. Porto Alegre: L\&PM, 2019.

LEITE, P. S. C. Produtos Educacionais em Mestrados Profissionais na Área de Ensino: uma proposta de avaliação coletiva de materiais educativos. VII Congresso IberoAmericano em Investigação Qualitativa (CIAIQ). Atas CIAIQ, 2018, p. 330-339.

LIPIETZ, A. Fordismo, fordismo periférico e metropolização. Ensaios FEE, v. 10, n. 2, p. 303-335, 1989. Disponível em:

https://revistas.fee.tche.br/index.php/ensaios/article/viewFile/1381/1745.

Acesso em: 15 jan. 2020.

MARX, K. O Capital: crítica da economia política: Livro I. São Paulo: Nova Cultural, 1996. 2 vols.

MARX, K.; ENGELS, F. A ideologia alemã. Tradução Luis Claudio de Castro e Costa. São Paulo: Martins Fontes, 1998.

MATTOSO, J. E. L. A desordem do trabalho. São Paulo: Scritta, 1995.

MELO, M. A. B.C. de. Interesses, atores e a construção histórica da agenda social do Estado no Brasil (1930/90). In Anuário publicado pela Associação Nacional de Pós-Graduação e Pesquisas em Ciências Socia. Ciências sociais hoje, 1991. São Paulo: Vértice, Editora Revista dos Tribunais, 1991, 262-287.

MENDES, F. S. O ovo do ornitorrinco: a trajetória de Francisco de Oliveira. Tese (doutorado) - Universidade Estadual de Campinas, Instituto de Filosofia e Ciências Humanas, Campinas, p. 316, 2015. Disponível em:

http://www.repositorio.unicamp.br/handle/REPOSIP/281087. Acesso em: 25 jan. 2020.

MÉSZÁROS, I. A Educação para além do capital. tradução Isa Tavares - 2. ed. São Paulo: Boitempo, 2008.

MÉSZÁROS, I. Para além do capital: rumo a uma teoria da transição. tradução Paulo Cezar Castanheira, Sérgio Lessa. 1.ed. revista. São Paulo: Boitempo, 2011.

MORAES, C. S. V. O ensino médio e as comparações internacionais: Brasil, Inglaterra e Finlândia. Educ. Soc. Campinas, v. 38, n. 139, p. 405-429, junho de 2017. Disponível em:

http://www.scielo.br/scielo.php?script=sci_arttext\&pid=S0101- 
73302017000200405\&lng=en\&nrm=iso. acesso em: 06 fev. 2020. http://dx.doi.org/10.1590/es0101-73302017177657.

OLIVEIRA, F. Crítica à razão dualista: o ornitorrinco. Boitempo Editorial, 2011.

RAMOS, M. Concepção do Ensino Médio Integrado. 2007. Disponível em: http://forumeja.org.br/go/sites/forumeja.org.br.go/files/concepcao_do_ensino_ medio_integra do5.pdf. Acesso em: 04 fev. 2020.

RAMOS, M. Ensino Médio Integrado: lutas históricas e resistências em tempos de regressão. In: ARAÚJJO, A. C.; SILVA; C. N. N. (Orgs.). Ensino Médio Integrado no Brasil: fundamentos, práticas e desafios. Brasília: Editora IFB, 2017. Disponível em:

http://www.anped.org.br/sites/default/files/images/livro_completo_ensino_med io_integrado_-_13_10_2017.pdf. Acesso em: 02 fev. 2020.

RODRIGUES, J. "Formar homens que o Brasil necessita, eis a tarefa da educação": o pensamento pedagógico empresarial na era Vargas. Revista HISTEDBR On-line, Campinas, n. 26, p. 160-182, 2007.

RODRIGUES, J. O Moderno Príncipe Industrial: o pensamento pedagógico da Confederação Nacional da Indústria. Campinas: Autores Associados, 1998.

SANTOS, V. C. Da era fordista ao desemprego estrutural da força de trabalho: mudanças na organização da produção e do trabalho e seus reflexos. Colóquio Internacional Marx e Engels, v. 6, 2009.

SAVIANI, D. O trabalho como princípio educativo frente às novas tecnologias. In: FERRETTI, C. J.; ZIBAS, D. M. L.; MADEIRA, F.; FRANCO, M. L. P. B. (Orgs.). Novas tecnologias, trabalho e educação: um debate multidisciplinar. 7. ed. Petrópolis: Vozes, 1994, p. 151-166.

SAVIANI, D. Sobre a concepção de politecnia. Rio de Janeiro: FIOCRUZ. Politécnico da Saúde Joaquim Venâncio, 1989.

SILVA, F. A. D. et. al.. História e Materialismo Histórico em Karl Marx e Friedrich Engels. In: VIII Colóquio Internacional Marx Engels, 2015. Disponível em: https://www.ifch.unicamp.br/formulario_cemarx/selecao/2015/posters2015/fra ncisco\%20du arte\%20da\%20silva\%20POSTER.pdf. Acesso em: 12 jan. 2020.

VIEIRA, J. A.; VIEIRA, M. M. M. Formação integrada do ensino médio com a educação profissional: o que dizem as pesquisas. Revista Thema, v. 13, n. 1 , p. 79-92, 2016. Disponível em:

http://revistathema.ifsul.edu.br/index.php/thema/article/view/287/182. Acesso em: 30 fev. 2020. 